\title{
Autosomal recessive amelia
}

INSERM

\section{Source}

INSERM. (1999). Orphanet: an online rare disease and orphan drug data base. Autosomal recessive amelia. ORPHA:1027

Autosomal recessive amelia is characterised by the absence of the upper limbs and severe underdevelopment of the lower limbs. Minor facial abnormalities (depressed nasal root, upturned nose, infra-orbital creases, prominent cheeks and micrognathia) were also reported. The syndrome has been described in three foetuses born to non consanguineous parents. 